\title{
ANTIOXIDANT ACTIVITY OF RHIZOME EXTRACTS OF COLEUS FORSKOHLII BRIQ
}

\author{
SHANMUGAM S, USHA RANI V, PRADEEP B V*
}

Department of Microbiology, Karpagam Academy of Higher Education, Coimbatore, Tamil Nadu, India. Email: bvpradeepku@gmail.com

Received: 04 May 2018, Revised: 11 July 2018

\begin{abstract}
Objective: The present study was on the analysis of the phytochemical constituents of Coleus forskohlii which was collected from five different areas in Tamil Nadu, where it is grown for commercial purposes.

Methods: C. forskohlii tubers were collected from five areas (Thiruvannamalai, Kanchipuram, Kallakuruchi, Salem, and Vandalur) of Tamil Nadu. Dried tubers were extracted with different solvents such as aqueous, ethanol, and acetone (polar) and petroleum and chloroform (non-polar). Extracts were
\end{abstract} evaluated for total phenol and flavonoid content and antioxidant activity evaluation by 1,1-diphenyl-2-picrylhydrazyl (DPPH) reduction.

Results: The highest DPPH radical scavenging activity (87.6\%) was observed in ethanol extract of rhizome collected from Thiruvannamalai area. Total phenol and flavonoid contents were found to be, respectively, $38.82 \pm 0.22 \mathrm{mg}$ gallic acid equivalents/g and $21.34 \pm 0.32$ quercetin equivalent/g.

Conclusion: The study clearly indicated the antioxidative potential of different extracts of $C$. forskohlii and this property may be useful in the preparation of drug formulations, health tonics, and cosmetics.

Keywords: Coleus forskohlii, Rhizome biomass, 1,1-diphenyl-2-picrylhydrazyl, Antioxidant activity, Phytochemicals.

(C) 2018 The Authors. Published by Innovare Academic Sciences Pvt Ltd. This is an open access article under the CC BY license (http://creativecommons. org/licenses/by/4. 0/) DOI: http://dx.doi.org/10.22159/ajpcr.2018.v11i11.27125

\section{INTRODUCTION}

Medicinal plants are the plants that are used for therapeutic purposes and the knowledge usually possessed by a small population and passed to their own progeny verbally. Hence, it is very much restricted, and recent efforts are taken by the Indian government to popularize this knowledge for the benefit of humankind through various schemes importing benefit to all the stakeholders. The bioactive compounds are produced by plants for their own defense against various threats such as insects and pathogens especially fungi as well as plant-eating animals, mainly cattle. These compounds are found to exhibit anti-inflammatory, antioxidant, antidiabetic, antimicrobial, and anticancer properties and hence have potency for herbal drug development against specific diseases apart from enhancing normal health. Hence, the present study on evaluation of antioxidant potency of Coleus forskohlii rhizome extracts.

Plants are used as the source of medicine in India from time immemorial, i.e., more than 300 years old, and 45,000 plants had been identified in herbal hot spots such as Eastern Himalayas, Western Ghats area, and Andaman and Nicobar Islands. As an awareness had been created among various sections of the people of the world, regarding the Ayurveda, the traditional medical system of India, it is gaining importance and it is true that the 2,50,000 practitioners had been reported in alternative medicines here against 7,00,000 modern medical practitioners. Especially, about $70 \%$ of rural Indian populations depend on Ayurveda and besides growing awareness in metros also. Herbal medicines (Kabiraji) and Ayurveda are considered as alternative medicines in India, which is otherwise known as the botanical garden of the world, where 25,000 drug formulations had been done through various studies in addition to 50,000 formulations already existing in folk and tribal communities.

C. forskohlii (common name: Indian Coleus; Marundu Koorkan in Tamil) is a common herb available in countries such India, Nepal, Myanmar, Sri Lanka, Thailand, and Africa. Forskolin, the primary compound in this herb, had been identified as a fat burner due to its cyclic adenosine monophosphate enhancing activity. Besides, its potential in treating heart as well as lung-related diseases had been proved [1]. Hence, the pharmaceutical industry is in high demand of this plant, and as generally, any herbal based bioactive component seemed to be influenced by many parameters such as season, region, and soil condition, the plant was collected from different areas in Tamil Nadu, and their total phenol and flavonoid content was estimated as well as antioxidant potential was evaluated.

Antioxidants are substances or compounds that inhibit oxidation. Antioxidants are having scavenging power of free radicals produced inside the human body which are responsible for many of the metabolic disorders such as atherosclerosis, arthritis, cancer, AIDS, central nervous system injury, and gastrointestinal disorders. [2]. In oxidation processes happening in biochemical reactions inside the human body, free radicals are produced and enzymes such as catalases and hydroperoxides act as natural antioxidants against them [3]. When antioxidants are consumed or fortified in food, they further slowdown the oxidation processes by fixing the stray electrons which are responsible for causing oxidative stress leading to cellular damage resulting in aging and various diseases such as cancer, diabetics, rheumatoid arthritis, cardiovascular diseases, chronic inflammation, and stroke.

\section{METHODS}

\section{Plant collection}

The tubers of $C$. forskohlii were collected from five areas of Tamil Nadu where it is commercially planted, i.e., Thiruvannamalai, Kanchipuram, Kallakuruchi, Salem, and Vandalur. They were identified by Dr. T. Sekar, an expert taxonomist working as Associate Professor in Pachaiyappa College, Chennai, India.

\section{Preparation of extract}

C. forskohlii tubers were dried to constant weight in shade (or) at $60^{\circ} \mathrm{C}$ in a hot air oven. A ground in a mortar and powdered well in which $1 \mathrm{~g}$ was taken and extracted with $15 \mathrm{ml}$ of different solvents such as aqueous, ethanol, and acetone (polar) and petroleum and chloroform 
(non-polar) in separate test tubes kept at $55^{\circ} \mathrm{C}$ for 5 min contact period.

Each extract was centrifuged at $9000 \mathrm{rpm}$ for $5 \mathrm{~min}$, and the procedure was repeated for 2-3 times to get a clear supernatant which was stored in a refrigerator at $5-10^{\circ} \mathrm{C}$ until use.

\section{Estimations of total phenolic content}

This was done by adopting the method of Singleton et al. [4]. About $0.5 \mathrm{ml}$ of extract was taken to which $0.5 \mathrm{ml}$ of water and $2 \mathrm{ml}$ of FolinCiocalteu reagent $\left(1: 5 \mathrm{H}_{2} \mathrm{O}\right)$ was added and kept for $3 \mathrm{~min} .10 \%(\mathrm{w} / \mathrm{v})$ $\mathrm{Na}_{2} \mathrm{CO}_{3}$ was added to this mixture and kept for $30 \mathrm{~min}$ after which reading was taken at $725 \mathrm{~nm}$ in a UV-spectrophotometer. Gallic acid was used as the standard. The total phenolic content was expressed as $\mu \mathrm{g}$ gallic acid equivalents (GAEs).

\section{Estimation of total flavonoids}

The method followed was as described by Kessler et al. [5]. $0.5 \mathrm{ml}$ of each extract ( $1 \mathrm{mg} / \mathrm{ml}$ ) was taken in separate test tubes, to which $0.1 \mathrm{ml}$ of $10 \% \mathrm{AlCl}_{3}$ and $0.1 \mathrm{ml}$ of $1 \mathrm{M}$ potassium acetate were added followed by $2.8 \mathrm{ml}$ of distilled water. The resultant mixture was shaken vigorously for thorough mixing and read at $420 \mathrm{~nm}$ in a UV-spectrophotometer. Quercetin was used as the standard, and the total flavonoid content was expressed in terms of quercetin equivalent (QE).

\section{DPPH assay to estimate antioxidant activity}

This procedure was done according to the method described by George et al. [6]. To $50 \mu \mathrm{l}$ of each extract taken in a separate well of a microtiter plate, $100 \mu \mathrm{l}$ of DPPH (in $0.1 \%$ methanol) reagent was added and kept for $30 \mathrm{~min}$ in a dark room and observed for color change. The extracts which changed to yellow were considered as strongly positive for antioxidant activity and proceeded for quantitative estimation as given below.

The above procedure was repeated with $100 \mu \mathrm{l}$ extract, and reading was taken at $517 \mathrm{~nm}$ in a UV-spectrophotometer. Butylated hydroxytoluene (BHT) was used as a standard. The following formula was used to calculate the free radical scavenging activity.

DPPH radical

Absorbance of control

scavenging activity $(\%)=\frac{- \text { Absorbanceof test sample }}{\text { Absorbance of control }} \times 100$

\section{Statistical analysis}

Each test was performed in triplicates, and the results were expressed as mean \pm standard deviation.

\section{RESULTS}

In the present investigation, tubers collected from Thiruvannamalai showed the maximum phenolic $(38.82 \pm 0.22 \mathrm{mg}$ GAE/g) as well as total flavonoid $(21.34 \pm 0.32 \mathrm{mg} \mathrm{QE} / \mathrm{g})$ content and coincided with the maximum antioxidant activity of $87.6 \%$. Antioxidant activity was found to be lesser compared to the standard BHT (97.2\%). The samples collected from Thiruvannamalai showed the maximum antioxidant activity $(87.6 \%)$ with the ethanolic extract. This was followed by samples of Kallakuruchi (76.2\%), Salem (73.7), Kanchipuram (68.3\%), and Vandalur (62.1\%) (Figs. 1-3). Regarding other solvents, also maximum values were obtained only for samples collected from this place.

\section{DISCUSSION}

Free radical production cannot be avoided as they are produced in almost all fundamental processes of aerobic organisms including plants. DPPH is a stable free radical compared to other antioxidants, and hence, it is considered as an important method to assess the potential of natural compounds to scavenge toxic oxygen molecules. The study clearly indicated that the various extracts of $C$. forskohlii act as a potent material to scavenge free radicals. The plant extract reduced DPPH to the hydrogen available by making unpaired electron to form pairs in the outer orbit, and hence, it is called antioxidant activity. This might be due to the high content of phenol and flavonoids as reported by many [7-9]. Among the different solvents used, extract done by ethanol showed the maximum antioxidant activity followed by acetone, aqueous (water), chloroform, and petroleum ether. This trend holds good for tubers collected from different places. The variations of antioxidant activity based on solvents might be due to their potential of extraction of these compounds from tuber biomass.

According to a study, petroleum ether extracts of Mucuna pruriens showed the maximum DPPH activity of $40.29 \%$ at $100 \mu \mathrm{g} / \mathrm{ml}$, whereas rutin (standard) showed 69.83\% [7]. They also found the different extents of DPPH scavenging activity for different solvents used, i.e., for ethyl acetate extract, $66.97 \%$, and for methanol extract, it was $49.83 \%$.

DPPH activity is concentration dependent (data not shown). In Cressa cretica $72.37 \%$ DPPH activity was observed at a concentration of

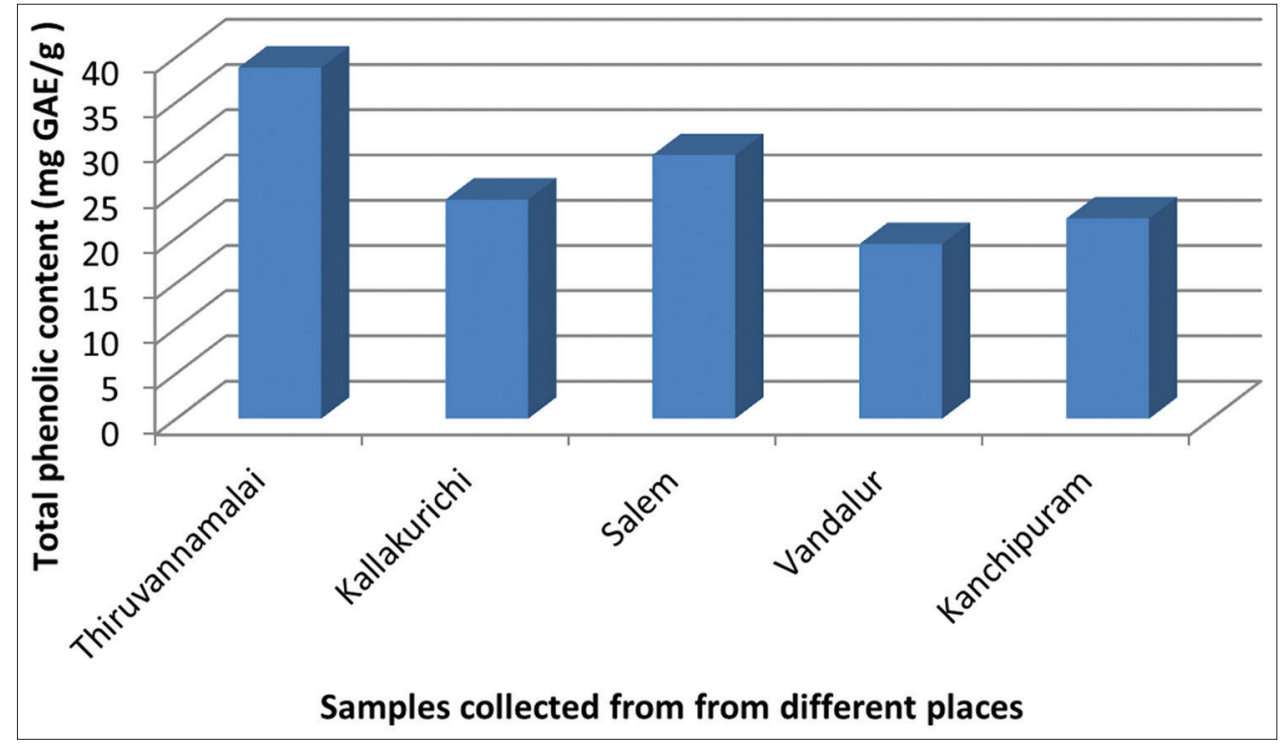

Fig. 1: Total phenolic content of Coleus forskohlii tubers collected from different places 


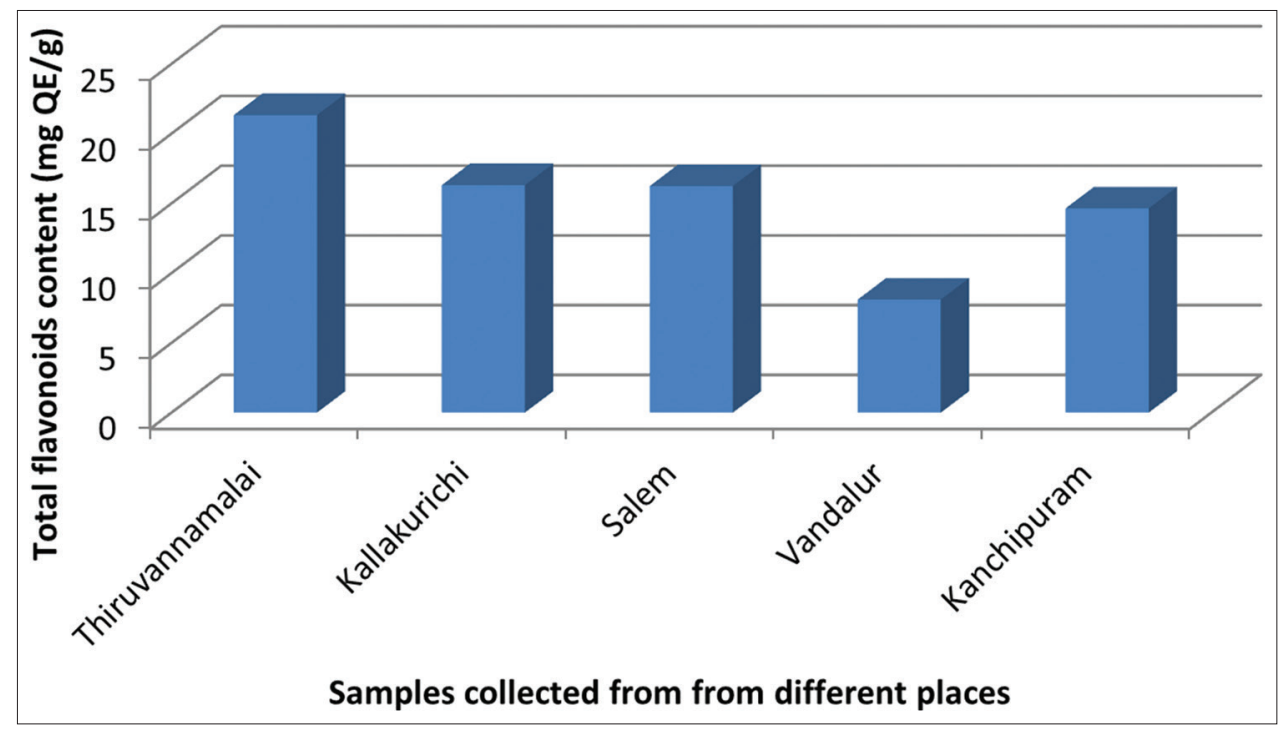

Fig. 2: Total flavonoids in Coleus forskohlii tubers collected from different places

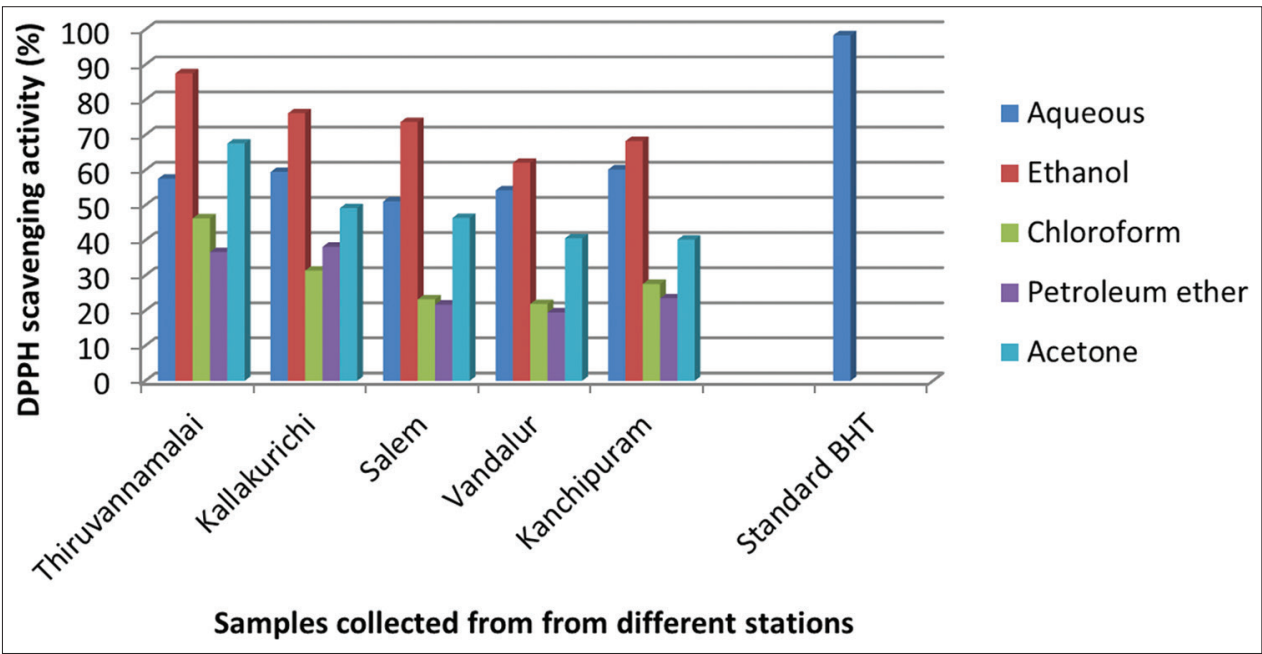

Fig. 3: Antioxidant activity of different solvent extracts of Coleus forskohlii tubers collected from different places

$250 \mathrm{mg} / \mathrm{ml}$ [10]. In another study, a plant species Salvia used for the tea preparations, especially in Mediterranean countries, possessed 51.19-118.13 mg GAE/g of total phenols, 820.71-1000.65 $\mu \mathrm{g} \mathrm{RE/g} \mathrm{of}$ flavonoids, and 67.26-138.44 mg AAE of antioxidant capacity [11].

Plants may contain varieties of phenolic compounds with varying antioxidant potential [12] which might be true in the present study also. As plant phenolics are the prime antioxidants or free radical terminators, their quantity must be estimated [2]. High content of phenolics was observed in 0 . sanctum $(48.93 \pm 0.24 \mathrm{mg} / \mathrm{g}), \mathrm{DPPH}$ activity was more in the methanolic extracts of all the five medicinal plants tested and the antioxidant values varied from $3.43 \pm 0.2$ and $48.93 \pm 0.24$, and strongest DPPH activity was noted in Desmodium gangeticum and Amaranthus caudatus [13]. The antioxidant activity of methanolic extracts of four Indian medicinal plants revealed the maximum of $77.0 \%$ DPPH activity for Hemidesmus indicus (stem) and the minimum of $20.06 \%$ for Holarrhena antidysenterica (bark) [14]. The ethanolic extracts of Alpinia speciosa and Alpinia calcarata rhizome showed antioxidant and free radical scavenging activity [15].

In a study done on the methanolic extract of different parts of the plant Lantana camara, total phenolic content was in the order of leaves $>$ flower $>$ root $>$ fruits so also the DPPH reduction activity [16]. The present study along with other studies given above insisted that the total phenol might be involved in quenching of free radicals, leading to higher antioxidant activity. This might be due to their hydrogen-donating property of their hydroxyl groups. Work on DPPH activity on Salvia amplexicaulis found that the methanol and ethanol extracts showed the highest DPPH reduction activity as in the present investigation. The methanol and ethanol extracts of $S$. amplexicaulis showed the highest DPPH reduction activity $[17,18]$ as in the present investigation. Interestingly in $S$. amplexicaulis, the ethanol extract of leaves showed maximum DPPH activity, whereas, in the whole plant, methanol extract showed the maximum DPPH reduction activity. However, in the present study, only tuber samples were used, as forskolin is an important compound in this plant, and it is present predominantly in tubers.

Different species of Salvia plant was attempted earlier [19], whereas in the present study, C. forskohlii available in different areas of Tamil Nadu was studied. The results showed the importance of the area of plantation related to pharmacologically important crops. Ludwigia octovalvis and Vitis thunbergii exhibited very strong scavenging of DPPH radicals when 26 species of different plants were tested and $\mathrm{IC}_{50}$ values were 4.6 and $24.1 \mu \mathrm{g} / \mathrm{ml}$, respectively [20]. Ginkgo biloba, a popular medicinal herb leaf extract, studied for its antioxidant activity showed an $\mathrm{IC}_{50}$ value of $930 \mu \mathrm{g} / \mathrm{ml}[21]$. 
The antioxidant activity of three methanolic rhizome extracts Hedychium spp. was studied and $60.86 \%$ of free radical scavenging activity as the highest was noted with Hedychium rubrum [22], whereas $71.21 \%$ of antioxidant capacity was observed with $C$. forskohlii [9]. Compared to these plants, the potency exhibited by tubers of $C$. forskohlii in the present study seemed to be more. The antioxidant property of $C$. forskohlii revealed the possibility of formulating functional foods from this plant extracts as high content of flavonoids and phenolics might have a preventive role in many diseases including heart diseases and cancer [23]. Red wine [24,25], carotenoid-containing fruits and vegetables [26], and their role in saving lives from heart diseases insist the food value of plants with antioxidative potential [27].

Flavonoids and DPPH activity had been reported in different plants by different researchers, for example, in leaf extracts of Stevia rebaudiana Bert. [28], Clusia fluminensis Planch. and Triana (Clusiaceae Lindl.) [29], and Sida cordata [30].

Oxidative stress generating free radicals seemed to be controlled by natural flavonoids in foods consumed by human beings as well as animals. The total flavonoids in methanolic extracts of three Hedychium spp. in H. spicatum, H. coronarium, and H. rubrum are to be, respectively, 4.22, 2.47, and $21.25 \mu \mathrm{g} / 100 \mathrm{~g}$ in dried rhizomes. Accordingly, 42.74\%, $32.42 \%$, and $60.86 \%$ of antioxidant activity in DPPH assay were obtained [22]. Similar results have been observed in various Hedychium spp. in different regions [31-33] and in Polyalthia longifolia [34]. As more than 6000 flavonoids in different plant species were reported, it became a practical issue, to estimate total flavonoids as an index of their antioxidant potential [35]. The oxygen with a double bond in the basic structure of flavonoids seemed to be responsible for their scavenging activity. The results of the present study are in agreement with various other researches who have done in different kind of samples opined that antioxidant activity might be due to phenols as well as flavonoids $[29,30]$.

\section{CONCLUSION}

The study clearly indicated that the antioxidative activity potential of different extracts of $C$. forskohlii might be due to phenols as well as flavonoids and these properties can be used in drug formulations as well as in exploiting this tuber for other purposes such as cosmetics and preparation of health tonics.

\section{ACKNOWLEDGMENT}

The authors sincerely thank the management, Karpagam Academy of Higher Education, Coimbatore - 641 021, Tamil Nadu, India, for their encouragement and support.

\section{AUTHORS' CONTRIBUTION}

SS: Collection of plant materials, acquisition, analyzed, interpretation of data, and wrote the manuscript. VU: In a consolidation of results. BVP: Reviewing and corrected the manuscript.

\section{CONFLICTS OF INTEREST}

The authors declare that they have no competing interests.

\section{REFERENCES}

1. Ordonez AA, Gomez JD, Vattuone MA, Isla MI. Antioxidant activities of Sechium edule (Jacq). Food Chem 2006;297:452-8.

2. Cook NC, Samman S. Flavonoids-chemistry, metabolism, cardio protective effects and dietary sources. J Nutr Biochem 1996;7:66-76.

3. Gaetani G, Ferraris A, Rolfo M, Mangerini R, Arena S, Kirkman H. Predominant role of catalase in the disposal of hydrogen peroxide within human erythrocytes. Blood 1996;87:1595-9.

4. Singleton VL, Orthofer R, Raventos RM. Analysis of total phenols and other oxidation substrates and antioxidants by means of folin-ciocalteu reagent. Methods Enzymol 1974;229:152-78.
5. Kessler M, Ubeaud G, Jung L. Anti- and pro-oxidant activity of rutin and quercetin derivatives. J Pharm Pharmacol 2003;55:131-42.

6. George H, Teng CM, Wu CL, Ko FN. Marchantin H as a natural antioxidant and free radical scavenger. Arch Biochem Biophys 1996;334:18-26

7. Muthu AK, Satheesh D, Dhas AS, Manavalan R. In vitro antioxidant activity of various extracts of whole plant of Mucuna pruriens (Linn). Int J Pharm Tech Res 2010;2:2063-70.

8. Sunitha K, Chary KB, Nimgulkar CC, Kumar BD, Rao DM. Identification, quantification and antioxidant activity of secondary metabolites in leaf and callus extracts of Coleus forskohlii. Int J Pharm Bio Sci 2013:4:1139-49.

9. Bajpai VK, Parka YH, Agrawal P. Studies on phytochemical analysis, antioxidant and lipid peroxidation inhibitory effects of a medicinal plant, Coleus forskohlii. Front Life Sci 2015;8:139-47.

10. Pryianka L, Partap S, Verma M, Jha KK. In vitro antioxidant activity of plant extract of Cressa cretica. Der Pharm Lett 2015;7:28-32.

11. Ozcan MM, Ozkan G. Determination of antioxidant activity and total phenol contents of two Salvia extracts. Indian J Tradit Knowledge 2014:14:226-30.

12. Shahidi F. Antioxidants in food and food antioxidants. Nahrung/Food 1992;44:158-63.

13. Veeru P, Kishor MP, Meenakshi G. Screening of medicinal plant extracts for antioxidant activity. J Med Plant Res 2009;3:608-12.

14. Zhain M, Aqil F, Agmad I. The in vitro antioxidant activity and total phenolic content of four Indian medicinal plants. Int J Pharm Pharm Sci 2009;8 Suppl 1:88-95.

15. Suja S, Mohanasundari L. Antioxidant and free radical scavenging activity of the mixture of ethanolic extracts of Alpinia speciosa and Alpinia calcarata rhizome. Int J Pharm Pharm Sci 2016;8:164-70.

16. Mahdi-Pour B, Jothy SL, Latha LY, Chen Y, Sasidharan S. Antioxidant activity of methanol extracts of different parts of Lantana camara. Asian Pac J Trop Biomed 2012;2:960-5.

17. Bejeli M, Rowshan V, Zakerin A. Comparision of total phenolic content and antioxidant activity of five Saliva species by FRAP and DPPH assay. Int J Pharrm Pharm Sci 2012;4:572-3.

18. Alimpic A, Oaldje M, Matevski V, Marin PD, Duletic-Lausevic S. Antioxidant activity and total phenolic and flavonoid contents of Salvia amplexicaulis Lam. Extracts. Arch Biol Sci 2014;66:307-16.

19. Sonja D, Ana AA, Danica P, Petar M, Dmitar L. Salvia officinalis of different origins - antioxidant activity, phenolic and flavonoid content of extracts. Agro Food Ind Hi Tech 2016;27:52-5.

20. Shyura LF, Tsunga JH, Chenb JH, Chiua CY, Lo CP. Antioxidant properties of extracts from medicinal plants popularly used in Taiwan. Int J Appl Sci Eng 2005;3:195-202.

21. Mazza G, Oomah BD. Chemistry, pharmacology and clinical applications of St. John's wort and Ginkgo biloba. In: Mazza G, Oomah BD, editors. Herbs, Botanicals and Teas. Lancaster, PA, U.S.A: Technomic Publishing Co. Inc.; 2000. p. 131-76.

22. Bag GC, Devi PG, Bhaigyabati T. Assessment of total flavonoid content and antioxidant activity of methanolic rhizome extract of three Hedychium species of Manipur alley. Int J Pharm Sci Rev Res 2015;30:154-9.

23. Kahkonen MP, Hopia AT, Vuorela HJ, Rauha JP, Pihlaja K, Kujala TS, et al. Antioxidant activity of plant extracts containing phenolic compounds. J Agri Food Chem 1999;47:3954-62.

24. Serafini M, Maiani G, Ferro-Luzzi A. Alcohol-free red wine enhances plasma antioxidant capacity in humans. J Nutr 1998;128:1003-7.

25. Carbonneau MA, Leger CL, Descomps B, Michel F, Monnier F. Improvement in the antioxidant status of plasma and low-density lipoprotein in subjects receiving a red wine phenolics mixture. J Am Oil Chem Soc 1998; 75:235-40.

26. Cao G, Booth SL, Sadowski JA Prior RL. Increases in human plasma antioxidant capacity after consumption of controlled diets high in fruit and vegetables. Am J Clin Nutr 1998;68:1081-7.

27. Knekt P, Jarvinen R, Reunanen A, Maatela J. Flavonoid intake and coronary mortality in Finland: A cohort study. Br Med J $1996 ; 312: 478-81$.

28. Gopalakrishnan B, Bawane AA, Akki KS, Hukkeri VI. Free radical scavenging activity of flavonoid containing leaf extracts of Stevia rebaudiana Bert. Anc Sci Life 2006;25(3-4):44-48

29. Carolina MA, Silva DA, Paiva SA. Antioxidant activity and flavonoid content of Clusia fluminensis Planch and Triana. An Acad Bras Cienc 2012;84:609-16.

30. Shah NA, Khan MR, Ahmad B, Noureen F, Rashid U, Khan RA. Investigation on flavonoid composition and anti free radical potential of Sida cordata. BMC Complement Altern Med 2013;13:276. 
31. Lu Y, Zhong CX, Wang L, Lu C, Li XL, Wang PJ. Antiinflammation activity and chemical composition of flower essential oil from Hedychium coronarium. Afr J Biotechnol 2009;8:5373-7.

32. Ho JC. Antimicrobial, mosquito larvicidal and antioxidant properties of the leaf and rhizome of Hedychium coronarium. J Chin Chem Soc 2011;58:563-7.

33. Sravani T, Paarakh PM. Evaluation of anthelmintic activity of
Hedychium spicatum Buch. Int J Res Pharm Sci 2011;2:66-8.

34. Mundhe KS, Kale AA, Gaikwad SA, Deshpande NR, Kashalkar RV. Evaluation of phenol, flavonoid contents and antioxidant activity of Polyalthia longifolia. J Chem Pharm Res 2011;3:764-9.

35. Khatiwora E, Adsul VB, Kulkarni MM, Deshpande NR Kashalkar RV. Spectroscopic determination of total phenol and flavonoid contents of Ipomoea carnea. Int J Chem Tech Res 2010;2:1698-701. 